\title{
National organ registry and allocation system remains remote
}

$\mathrm{H}$ opes that Canada will have a national organ transplant registry and allocation system in the foreseeable future remain remote, although Canadian Blood Services officials are optimistic that three small registries will inch administrators in that direction.

The nonprofit organization was tasked with developing a national registry and allocation system in 2008 and opted to start by developing specialized registries in three areas that cater to a small fraction of waiting transplant recipients.

But plans to roll out a broader strategy for some manner of national registry and allocation system remain in the developmental phase, says Chris Brennan, communications manager of the organization's Organs and Tissues division. Canadian Blood Services continues to have discussions with provincial and territorial governments about means of standardizing the process of organ allocation, he adds.

One of the three specialized registries, the Living Donor Paired Exchange, was launched in 2009, while the registry for "urgent status patients" is expected to become operational this fall and one for "highly sensitized kidney patients" will be initiated in 2012 .

Funding for development of the specialized registries was made possible under a \$35-million, five-year agreement between the federal, provincial and territorial governments.

Organ donation and allocation in Canada has long been plagued by jurisdictional wrangles. When Canadian Blood Services was asked to take over the file in 2008, it was hoped that the goodwill the agency has developed through the years in its oversight of blood donations would help it negotiate the perilous jurisdictional waters, which have resulted in a hodgepodge of donor registration processes and a range of waiting times for transplant candidates across the nation.

Still observers are hopeful that the specialized registries will lay the spade-

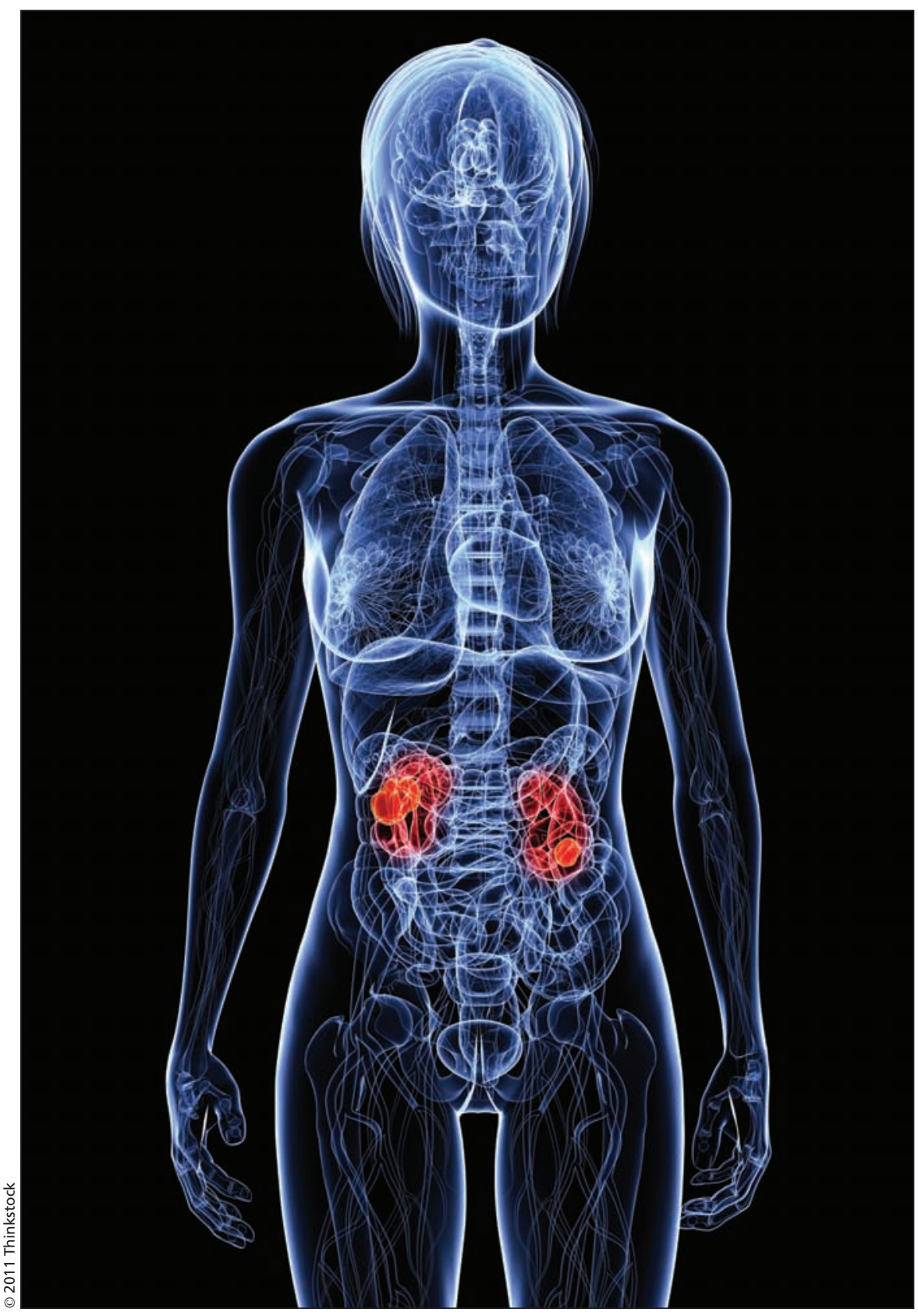

A Canadian registry for "highly sensitized kidney patients" will be initiated in 2012.

work for a national allocation system for all organs. At a minimum, they should help to create some consistency between jurisdictions, says Dr. Ian Alwayn, surgical director of kidney transplants at the Queen Elizabeth II Health Sciences Centre in Halifax, Nova Scotia. "The goal of the national organ registries is to gain transparency in the way organs are allocated and to set standard rules ... so that there is no discrepancy in the way that organs are allocated from one province to another."

Brennan says the Living Donor Paired Exchange, which became operational in November 2010, has 
been "really successful." The program matches living donors with compatible recipients. Patients who find a willing donor whose kidney isn't compatible can essentially trade that kidney for one that is compatible and offered for trade by a different donor-recipient pair. That has often necessitated multiple exchanges.

Brennan says Canadian Blood Services remains hopeful that the urgentneed registry will launch this fall. The wait list, which is intended for those who are "hours away from death," will be Web-based and updated in real time. It will replace the "status 4" urgent case list now maintained by the London Health Sciences Centre (www.cmaj.ca/lookup /doi/10.1503/cmaj.061256).

The national registry for highly sensitized kidney patients, meanwhile, hopes to find organ matches for people with antibodies that make finding a match difficult.

Brennan offered no explanation for why a draft proposal for a national organ and tissue registry has been delayed. Canadian Blood Services had indicated they would unveil such a draft plan as early as 2009.

Also unresolved are mechanisms to make organ donor registration less cumbersome. Currently, registration processes vary significantly by provinces. In British Columbia, donors can register consent online. Ontario requires residents to forward a form to the nearest ServiceOntario centre to get a sticker or a new health card. But the province is considering a move toward a
Web-based registry following a recommendation from its auditor general.

Although Health Canada is investing roughly $\$ 3.6$ million annually over five years to promote organ donations, public opinion surveys show that many Canadians remain unaware about how to register as donors (www.blood.ca /CentreApps/Internet/UW_V502_Main Engine.nsf/resources/Releases/\$file/IPS OS+Report.pdf).

Alwayn says a more streamlined approach to donor registration would encourage more donations, which will become ever more essential as the need for organs rises with the average age of Canada's population. - Samia Madwar, Ottawa, Ont.

CMAJ 2011. DOI:10.1503/cmaj.109-3889 